\title{
VANTAGENS E LIMITAÇÕES DO SEBO BOVINO ENQUANTO MATÉRIA-PRIMA PARA A INDÚSTRIA BRASILEIRA DE BIODIESEL
}

\author{
L. H. R. VARÃO*, T. A. L. SILVA, H. D. Z. ZAMORA e D. PASQUINI \\ Universidade Federal de Uberlândia \\ franzleandro_16@yahoo.com.br
}

Submetido 25/08/2016 - Aceito 18/10/2017

DOI: $10.15628 /$ holos. 2017.5010

\section{RESUMO}

Recentemente, a escassez global dos combustíveis fosseis, além de questões políticas, econômicas e ambientais impulsionaram a busca por combustíveis oriundos de fontes renováveis. Neste contexto, o biodiesel surge como um promissor combustível sucedâneo ao diesel mineral, seja parcial ou totalmente. O Brasil é o segundo maior produtor e consumidor mundial de biodiesel, sendo que o sebo bovino é o segundo insumo mais utilizado para a produção deste biocombustível no país, atrás apenas da soja. Diante disso, este artigo de revisão bibliográfica aborda as principais vantagens e limitações relacionadas ao uso desta matéria-prima para obtenção de biodiesel no Brasil, destacando fatores econômicos e ambientais, suas características físico-químicas, além de aspetos relativos à sua cadeia produtiva.

PALAVRAS-CHAVE: Vantagens, Limitações, Sebo bovino, Biodiesel.

\section{ADVANTAGES AND LIMITATIONS OF BEEF TALLOW AS FEEDSTOCK FOR BRAZILIAN BIODIESEL INDUSTRY}

\begin{abstract}
Recently, the global shortage of fossil fuels, as well as political, economic and environmental issues, have boosted the search for fuels obtained from renewable sources. In this context, biodiesel emerges as a promising substitute fuel for mineral diesel, either partially or totally. Brazil is the second largest biodiesel producer and consumer in the world and beef tallow is the second most used feedstock to produce this biofuel
\end{abstract}

in the country, after soybean. Thus, this review deals with the main advantages and limitations related to beef tallow use as source for biodiesel production in Brazil. It is emphasized beef tallow economical and environmental factors, its physical and chemical properties, as well as aspects concerning its production chain.

KEYWORDS: Advantages, Limitations, Beef tallow, Biodiesel. 


\section{INTRODUÇÃO}

Desde o final do século XIX até a atualidade o petróleo tem sido a principal fonte de energia no mundo. Porém, questões como o aumento dos preços do óleo cru, aliado ao esgotamento das reservas e a preocupação com problemas ambientais ocasionados pela queima de combustíveis fósseis, tem evidenciado a necessidade da busca por novos recursos energéticos que sejam limpos, renováveis e capazes de suprir a demanda energética global (Villela, 2014; Bello \& Daniel, 2015).

Nesta perspectiva, enquadram-se os biocombustíveis, os quais são produtos derivados de diferentes biomassas, dentre as quais estão: cana-de-açúcar, resíduos florestais, óleos vegetais, gorduras de origem animal, etc. (Neves, 2011; Cárdenas, 2011).

O Brasil exibe grande potencial para produção de biocombustíveis, pois possui vantagens agronômicas, em função de sua geografia; apresenta clima favorável, altas taxas de luminosidade e temperaturas médias anuais que apresentam variação de acordo com a região; bem como, disponibilidade hídrica e regularidade de chuvas (Melo, 2010).

No país, os biocombustíveis mais utilizados são o etanol e o biodiesel (Neves, 2011). 0 biodiesel é considerado um substituto promissor aos combustíveis fósseis, notadamente para o óleo diesel, em decorrência de suas propriedades físico-químicas similares, matéria-prima abundante, baixa toxicidade e fácil biodegradabilidade; além de não demandar adaptações nos motores do ciclo diesel e infraestrutura de armazenamento (Fernandes et al., 2012; Chen, Jia, Guo, Xiang \& Lou, 2014); e poder ser usado puro ou misturado ao diesel (Santos, 2014).

Sua produção ocorre a partir de fontes biológicas renováveis, como, óleos vegetais, gorduras animais ou óleos e gorduras residuais (Neves, 2011; Aransiola, Ojumu, Oyekola, Madzimbamuto \& Ikhu-Omoreggbe, 2014). Quanto à sua composição, é formado por ésteres de ácidos graxos de cadeia longa, os quais são produzidos majoritariamente por transesterificação de triglicerídeos ou esterificação de ácidos graxos com metanol ou etanol (Wang et al., 2015).

No Brasil, as principais matérias-primas utilizadas pela indústria de biodiesel são a soja e o sebo bovino, responsáveis por mais de 95\% de todo o montante produzido em 2015 (Associação Brasileira das Indústrias de Óleos Vegetais [ABIOVE], 2016; Empresa de Pesquisa Energética [EPE], 2016).

O sebo bovino representa uma opção de insumo para a indústria nacional de biocombustíveis, em função, sobretudo, da sua alta produção e seu baixo custo de comercialização (Díaz, 2012). Além disso, o mercado do biodiesel representa uma alternativa de destinação correta para um resíduo com alto potencial poluente que é frequentemente ligado a problemas ambientais por causa de seu descarte irregular no meio ambiente (Cunha Jr. et al., 2013).

Este trabalho, mediante revisão de literatura, aborda o sebo bovino enquanto matériaprima para a indústria de biodiesel no Brasil. Neste sentido, são apresentados aspectos gerais sobre esse insumo, como, suas características físico-químicas e as de seu biodiesel; além das potencialidades e limitações de sua utilização para a produção do referido biocombustível. 


\section{SEBO BOVINO: ASPECTOS GERAIS}

O sebo bovino é definido como sendo um produto obtido a partir de resíduos de tecidos bovinos, processados em digestores de batelada contínuos, extração de gordura por prensas, centrífuga ou pelo método de extração de solventes orgânicos (Cunha, 2008). E, em geral, a sua produção é realizada por graxarias ${ }^{1}$, as quais podem ser vinculadas aos frigoríficos ou abatedouros por integração vertical, o que possibilita que a matéria-prima seja processada mais rapidamente, ou também por unidades de negócio independentes e desverticalizadas (Pacheco, 2006a; Levy, 2011).

Trata-se de uma matéria-prima muito utilizada pela indústria de sabões. Além disso, é empregado na produção de cosméticos, tintas e vernizes, limpeza e higiene, fabricação de rações animais, dentre outras. Contudo, seu uso para consumo humano é proibido no Brasil (Andrade Filho, 2007; Levy, 2011).

O sebo é uma gordura obtida como subproduto da cadeia produtiva da indústria de carne bovina. De maneira geral, seu custo é relativamente baixo, visto que é extraído como resíduo a partir de partes menos nobres, como, por exemplo, da carcaça (Cunha, 2008; Barros \& Jardine, 2016b). Segundo Levy (2011), em média, um boi oferece entre 15 e 17 kg de sebo aproveitável.

De modo simplificado, o processo de obtenção do sebo bovino (Figura 1) ocorre a partir do cozimento das vísceras e ossos obtidos após o abate do animal, além de partes não comestíveis ou condenadas, de resíduos gordurosos presentes na água usada para lavar os cortes ao longo da linha de processamento e a consequente separação da gordura presente nestes compostos. A retirada da gordura pode ser feita tanto por prensagem quanto por centrifugação ou utilizando solventes orgânicos (Pacheco, 2006b; Andrade Filho, 2007; Levy, 2011).

\footnotetext{
${ }^{1}$ As graxarias coletam e processam subprodutos e/ou resíduos provenientes do abate de animais e da limpeza das carcaças e das vísceras, como, sangue, cascos, chifres, partes não comestíveis e condenadas pela inspeção sanitária, ossos e aparas de gordura e carne da desossa, vísceras não comestíveis, bem como resíduos de processamento ou industrialização da carne. Além disso, também abordam subprodutos oriundos de: açougues, peixarias, salsicharias, matadouros de bovinos, aves, suínos e outros animais usados no consumo humano (Pacheco, 2006a; Rebouças, Zanini, Kiperstok, Pepe \& Embiruçu, 2010).
} 


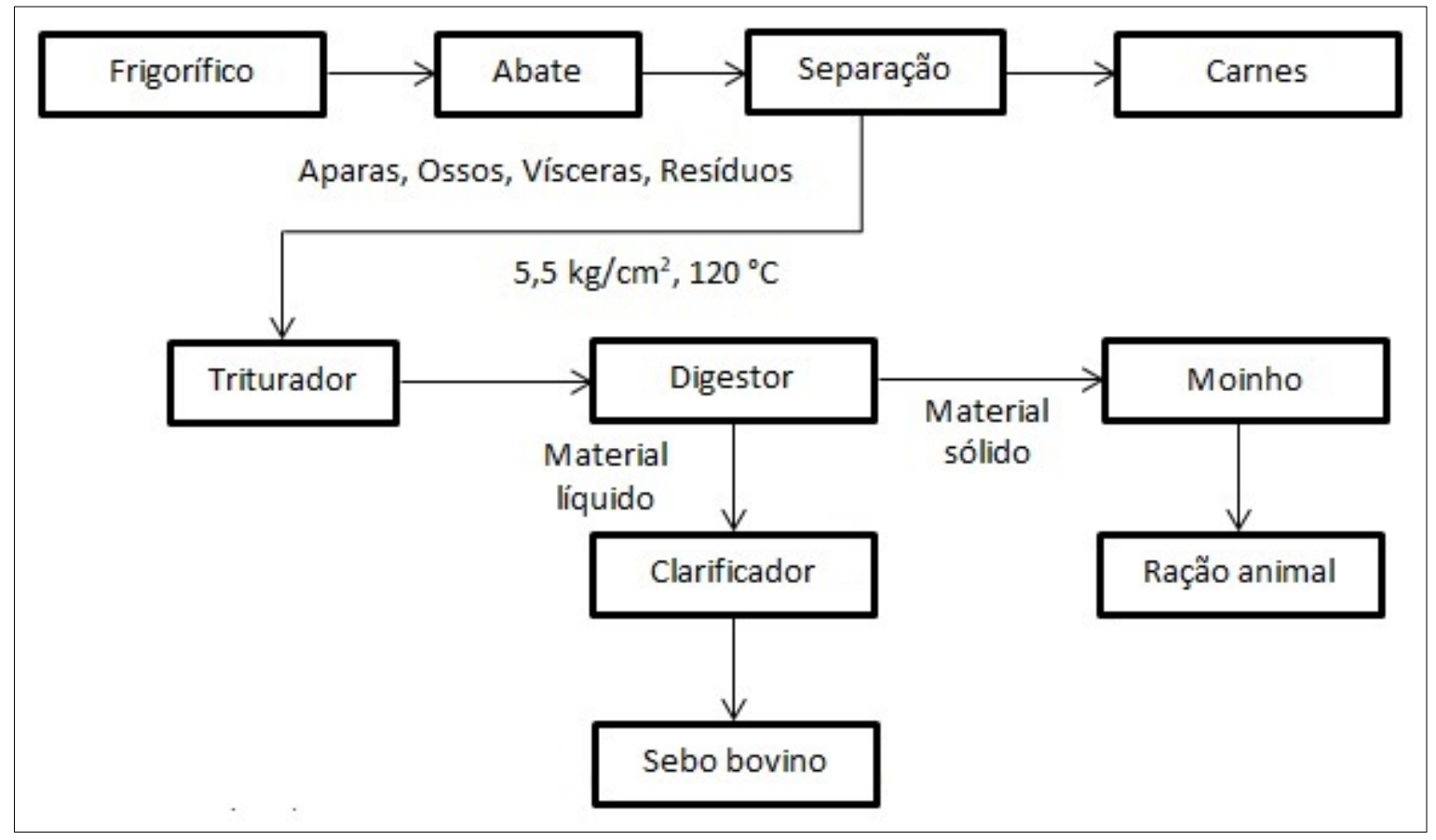

Figura 1: Fluxograma de produção do sebo bovino.

Fonte: Adaptado de Andrade Filho (2007).

Após a realização deste processo, obtém-se o sebo bovino, produto cujo aspecto apresentado é pastoso à temperatura ambiente, de cor esbranquiçada e com odor característico (Andrade Filho, 2007).

Krause (2008) apresenta as premissas para produção e manutenção da qualidade do sebo bovino: (I) seleção e controle de qualidade das gorduras utilizadas; (II) uso de modernos processos de abate; (III) em conjunto com uma boa estocagem e processo de manuseio. As características físico-químicas para um bom produto são apresentadas na Tabela 1.

Tabela 1: Características físico-químicas ideais para um sebo bovino de boa qualidade.

\begin{tabular}{c|c|c}
\hline Índices & Unidades & Valores de referência \\
\hline Peso específico $\left(25^{\circ} \mathrm{C}\right)$ & $\mathrm{g} / \mathrm{cm}^{3}$ & $0,903-0,907$ \\
Índice de refração $\left(40^{\circ} \mathrm{C}\right)$ & - & $1,450-1,458$ \\
Índice de iodo & $\mathrm{g} \mathrm{I}_{2} / 100 \mathrm{~g}$ & $33-47$ \\
Índice de saponificação & $\mathrm{mg} \mathrm{KOH} / \mathrm{g}$ & $190-200$ \\
Matéria de insaponificável & $\%$ & $<0,5 \%$ \\
Ponto de fusão & ${ }^{\circ} \mathrm{C}$ & $45-48$ \\
\hline
\end{tabular}

Fonte: Levy (2011).

Para que o sebo seja aplicado na produção de biodiesel sem demandar pré-tratamentos, parâmetros, como, acidez, umidade, insolúveis e insaponificáveis devem ser adequadamente controlados, a fim de obter-se uma maior eficiência na transesterificação (Andrade Filho, 2007; Barros \& Jardine, 2016b). Neste sentido, os valores máximos desejáveis para um sebo bovino de qualidade superior são apresentados na Tabela 2. 
Tabela 2: Especificação do sebo bovino de qualidade superior.

\begin{tabular}{c|c}
\hline Característica & Limite Máximo \\
\hline Ácido Graxo Livre (\%) & 1,0 \\
Umidade (\%) & 0,3 \\
Impurezas (\%) & 0,1 \\
Insaponificáveis (\%) & 0,6 \\
Título (\%) & $40-46$ \\
\hline
\end{tabular}

Fonte: Andrade Filho (2007).

Em relação à conversão dessa matéria-prima em óleo, 01 quilograma de sebo resulta em 01 quilograma de óleo. Comparativamente, 01 quilograma de soja gera 170 gramas de óleo (Krause, 2008). Adicionalmente, segundo Levy (2011), a produção de biodiesel a partir de um sebo bovino de boa qualidade deve possuir um aproveitamento de aproximadamente $93 \%$ da reação.

Para produção de biodiesel, o sebo bovino deve se encontrar no estado líquido. Portanto, o transporte da graxaria até a usina de biodiesel deve ser realizado em sistema adequadamente aquecido (Levy, 2011; Barros \& Jardine, 2016b).

\subsection{Composição química}

O sebo é composto basicamente por triglicerídeos (Barros \& Jardine, 2016b); apresentando maior quantidade de ácidos graxos de cadeia saturada (Tabela 3). Comparativamente, os óleos de origem vegetal são compostos majoritariamente por ácidos graxos insaturados. Assim, as distinções entre ambos são químicas e estão nos tipos e distribuições dos ácidos graxos combinados com o glicerol (Cunha, 2008; Díaz, 2012).

Tabela 3: Composição química em ácidos graxos do óleo de soja e do sebo bovino.

\begin{tabular}{c|c|c|c}
\hline Ácido graxo & Fórmula & Soja (\%) & Sebo bovino (\%) \\
\hline Láurico & C12:0 & 0,1 & 0,1 \\
Mirístico & C14:0 & 0,1 & 2,8 \\
Palmítico & C16:0 & 10,2 & 23,3 \\
Esteárico & C18:0 & 3,7 & 19,4 \\
Oleico & C18:1 & 22,8 & 42,4 \\
Linoleico & C18:2 & 53,7 & 2,9 \\
Linolênico & C18:3 & 8,6 & 0,9 \\
Outros & - & 0,8 & 8,2 \\
\hline
\end{tabular}

Fonte: Adaptado de Tan, Lu, Nie, Deng e Wang (2010); Aransiola et al. (2014).

A composição química e as propriedades da matéria-prima usada influenciam nas características do combustível obtido, como, por exemplo, a densidade, o número de cetanos e o teor de enxofre (Teixeira et al., 2010; De Quadros et al., 2011). Dessa forma, o perfil de ácidos graxos do sebo influi diretamente as características de seu biodiesel, tanto em relação às vantagens de sua utilização quanto às limitações e/ou restrições de seu uso (vide seção 5.2.3).

\section{CARACTERÍSTICAS FÍSICO-QUÍMICAS DO BIODIESEL DE SEBO BOVINO}

O biodiesel obtido a partir de gorduras animais e o de óleos vegetais apresentam composições semelhantes. No entanto, há algumas distinções, a principal delas é que o 
biocombustível oriundo de gordura animal contém mais ésteres de ácidos graxos saturados. A maior concentração dos ácidos esteárico e palmítico é responsável pelas propriedades únicas do sebo, que são o alto ponto de fusão e a alta viscosidade (Teixeira et al., 2010).

$\mathrm{Na}$ Tabela 4 é descrito o perfil de ácidos graxos para biodieseis produzidos a partir do sebo bovino e óleo de soja. O biodiesel proveniente da soja é composto majoritariamente por ácidos graxos insaturados, $84,5 \%$, sendo o ácido linoleico o mais representativo. Por outro lado, o biocombustível oriundo do sebo possui composição mais equilibrada de ácidos graxos saturados e insaturados, respectivamente, 55,5\% e 44,5\%; sendo o ácido oleico o principal constituinte.

Tabela 4: Composição de ácidos graxos dos biodieseis de óleo de soja e sebo.

\begin{tabular}{c|c|c|c}
\hline Ácido graxo & Fórmula & \multicolumn{2}{|c}{ Biodiesel } \\
\cline { 3 - 4 } & & Soja (\%) & 4,0 \\
\hline Mirístico & C14:O & 0,0 & 27,0 \\
Palmítico & C16:0 & 10,0 & 24,0 \\
Esteárico & C18:0 & 4,0 & 40,0 \\
Oleico & C18:1 & 23,0 & 3,0 \\
Linoleico & C18:2 & 53,0 & 0,5 \\
Linolênico & C18:3 & 8,0 & 0,5 \\
Eicosanóico & C20:0 & 1,0 & 1,0 \\
Gadolênico & C20:1 & 0,5 & 0,0 \\
Bêenico & C22:0 & 0,5 & 0 \\
\hline
\end{tabular}

Fonte: Adaptado de Glaude, Fournet, Bounaceur e Molière (2010).

A Tabela 5 aborda propriedades físico-químicas para biodieseis obtidos a partir do óleo de soja e de sebo e seus respectivos limites estabelecidos na Resolução ANP № 45, de 2014, da Agência Nacional do Petróleo, Gás Natural e Biocombustíveis [ANP] (2014). Observa-se que para ambos os biodieseis apenas a estabilidade oxidativa está abaixo do valor mínimo determinado pela legislação vigente. Este problema, no entanto, segundo Yaakob et al. (2014), pode ser equacionado mediante a adição de antioxidantes, os quais inibem o processo de oxidação pela extensão do período de indução do biodiesel.

Tabela 5: Propriedades físico-químicas dos biodieseis de óleo de soja e sebo.

\begin{tabular}{c|c|c|c|c}
\hline Propriedade & Unidade & Soja & Sebo & Limites ANP \\
\hline Número de cetano & - & 51,8 & 60,9 & Anotar \\
Massa específica a $20^{\circ} \mathrm{C}$ & $\mathrm{kg} / \mathrm{m}^{3}$ & 882,8 & 874,3 & 850,0 a 900,0 \\
Viscosidade cinemática a $40^{\circ} \mathrm{C}$ & $\mathrm{mm}^{2} / \mathrm{s}$ & 4,29 & 4,83 & 3,0 a 6,0 \\
Ponto de fulgor & ${ }^{\circ} \mathrm{C}$ & 158,8 & 157,2 & mín. 100,0 \\
Índice de iodo (g/100g) & - & 126,0 & 54,5 & Anotar \\
Estabilidade à oxidação a 110ㅇ & $\mathrm{h}$ & 5,0 & 7,53 & mín. 8,0 \\
Índice de acidez & $\mathrm{mg} \mathrm{KOH} / \mathrm{g}$ & 0,32 & 0,30 & máx. 0,50 \\
\hline
\end{tabular}

Fonte: Giakoumis (2013); ANP (2014); Silva et al. (2015).

\section{REPRESENTATIVIDADE DO SEBO BOVINO NA INDÚSTRIA DE BIODIESEL BRASILEIRA}

Em 2015 o volume de biodiesel produzido no Brasil atingiu 3,9 bilhões de litros, montante $15 \%$ superior a 2014 , com 3,4 bilhões. Assim, o país manteve-se como o segundo maior produtor e 
consumidor mundial de biodiesel, atrás apenas dos EUA e à frente de Alemanha e Argentina (EPE, 2016).

As gorduras de origem animal têm se mantido entre as principais matérias-primas que compõem a cadeia produtiva deste biocombustível no país desde 2008 (ABIOVE, 2016), quando o Governo Federal estabeleceu a obrigatoriedade de adição de um percentual mínimo deste biocombustível ao óleo diesel comercializado em todo o território nacional (Padula, Santos, Ferreira \& Borenstein, 2012).

Dentre as gorduras animais, o sebo é o mais representativo nacionalmente. Também podem ser utilizados outros resíduos, como, os óleos de peixe e de mocotó, a banha de porco e a gordura de frango (Barros \& Jardine, 2016b).

Em 2015 o sebo se manteve como o segundo principal insumo para o biodiesel no país, com participação de 19,2\%, atrás apenas do óleo de soja, com aproximadamente $77,4 \%$ (ABIOVE, 2016) (Tabela 6).

Tabela 6: Participação de matérias-primas para a produção de biodiesel (\%) em 2015.

\begin{tabular}{c|c}
\hline Matéria-prima & Participação na produção de biodiesel (\%) \\
\hline Óleo de soja & 77,4 \\
Gordura animal & 19,2 \\
Óleo de algodão & 2,0 \\
Óleo de fritura & 0,4 \\
Outros materiais graxos & 1,0 \\
\hline
\end{tabular}

Fonte: ABIOVE (2016).

\section{VANTAGENS E LIMITAÇÕES DO SEBO BOVINO COMO INSUMO PARA PRODUÇÃO DE BIODIESEL}

\subsection{Vantagens}

O sebo bovino apresenta grande potencial de utilização pela indústria de biodiesel no Brasil. Em função, sobretudo, de aspectos de ordem econômica, ambiental e de suas características energéticas e físico-químicas.

\subsubsection{Fatores econômicos}

A principal vantagem do sebo para o biodiesel no Brasil é a grande produção nacional deste insumo, o que o torna uma matéria-prima de baixo custo e com disponibilidade imediata em áreas agroindustriais (Barros \& Jardine, 2016b).

Os preços do sebo são historicamente baixos (Teixeira et al., 2010). O que se justifica pelo fato do Brasil possuir o segundo maior rebanho bovino mundial, atrás apenas da Índia, e o maior rebanho comercial do mundo (Ministério da Agricultura, Pecuária e Abastecimento [MAPA], 2014b). Segundo dados do Ministério da Agricultura, Pecuária e Abastecimento (MAPA), em 2015, o rebanho brasileiro totalizou 215.002.619 cabeças de gado, sendo 213.819 .516 de bovinos e 1.183.103 de bubalinos (MAPA, 2016b). Estima-se que anualmente sejam abatidos mais de 40 milhões de cabeças de gado no país, o que representa um montante de aproximadamente 800 
milhões de quilogramas de sebo (MAPA, 2014a). Em 2015 a indústria nacional de biodiesel utilizou mais de 675 mil toneladas deste insumo (União Brasileira do Biodiesel e Bioquerosene [UBRABIO], 2016).

Outros aspectos favoráveis à utilização deste insumo pela indústria de biodiesel são:

$\mathrm{O}$ alto rendimento médio do processo de conversão do sebo em óleo, de modo que 01 quilograma de insumo gera 01 quilograma de óleo (Santos, 2010). Sendo que na transesterificação, uma matéria-prima de boa qualidade pode proporcionar rendimentos de até 93\% (Levy, 2011).

Além do direcionamento à produção de biodiesel, pode ser também uma fonte importante de ácidos graxos de alto valor agregado (Díaz, 2012).

Os pontos de oferta do sebo estão localizados próximo aos grandes centros urbanos consumidores de diesel mineral (Andrade Filho, 2007).

Por se tratar de um subproduto, o seu direcionamento para a indústria de biocombustíveis não representa um problema para o equilíbrio entre a produção de alimentos e a de energia (Levy, 2011; Severgnini \& Langer, 2011).

Unidades produtoras de biodiesel podem ser acopladas a plantas industriais abatedoras de animais. O que pode representar economia ao produtor de biocombustível ao diminuir gastos com transporte de matéria-prima e garantir o abastecimento ao longo do ano, pois não proporciona exposição a eventuais quebras de safra (Santos, 2010; Pires, 2012).

\subsubsection{Aspectos ambientais}

O direcionamento do sebo para sua conversão em biodiesel denota uma alternativa de destinação correta para este resíduo, cujo potencial poluente é alto e representa frequentemente um problema ambiental (Levy, 2011; Cunha Jr. et al., 2013).

Nesta perspectiva, Díaz (2012) destaca que antes do estabelecimento do Programa Nacional de Produção e Uso do Biodiesel (PNPB), alguns dos procedimentos adotados por frigoríficos e curtumes quanto à destinação final do sebo abrangia o seu enterro ou sua queima em caldeiras.

Contudo, ambos os procedimentos envolvem riscos de ocorrência de danos ambientais. Primeiramente, a disposição direta no meio ambiente de gorduras de origem animal, sem a realização de tratamentos prévios, pode provocar a contaminação de solos e lençóis subterrâneos; bem como a eutrofização das águas de rios e córregos. Já no segundo caso, o inconveniente ocasionado é a emissão de acroleína, em função da queima da glicerina presente na gordura (Santos, 2010; Levy, 2011; Díaz, 2012).

Outro aspecto ambientalmente favorável é que a cadeia de produção do sebo emite menores quantidades de dióxido de carbono $\left(\mathrm{CO}_{2}\right)$ que algumas das principais matérias-primas direcionadas à indústria de biodiesel no mundo, como colza e soja. Isto pode ser constatado mediante as Análises de Ciclo de Vida do sebo e de óleos vegetais (Díaz, 2012). 


\subsubsection{Características energéticas e físico-químicas}

Confrontado com o biodiesel produzido a partir de óleos vegetais, o produto oriundo de gorduras animais apresenta vantagens, como, alto valor calorífico, maior número de cetano, maior estabilidade à oxidação e menor índice de iodo (Krause, 2008; Barros \& Jardine, 2016b).

\subsection{Limitações}

Os principais problemas associados à utilização da gordura bovina pela indústria de biocombustíveis estão relacionados à: sua obtenção, qualidade da matéria-prima, e algumas características físico-químicas que lhe são intrínsecas.

\subsubsection{Obtenção de matéria-prima}

Alguns dos principais problemas relacionados à utilização do sebo pela indústria de biocombustíveis dizem respeito à sua obtenção junto a seus produtores. Nesta direção, destacamse:

A inexistência de um mercado organizado para a comercialização desta gordura no país, que se dá em virtude da falta de coordenação na cadeia produtiva entre frigoríficos/graxarias (produtores de sebo) e usinas de biodiesel. Este cenário provoca a existência de exíguas informações a respeito das transações envolvendo fornecedores e as unidades produtoras de biodiesel, o que gera problemas relativos às oscilações do preço deste produto e sobre a qualidade deste insumo (Levy, 2011; Martins \& Carneiro, 2013).

A disponibilidade de sebo no mercado está relacionada com a produção de carne, assim existe uma relação entre a demanda de gordura bovina e o mercado de carne, o que gera oscilações no mercado de sebo, no sentido da escassez e do excedente do produto (Levy, 2011).

O sistema de formação de preços do sebo bovino. A ausência de um mercado nacional estável faz com que muitos produtores de biodiesel se baseiem no mercado do óleo de soja para tomada de suas decisões, assim, recorrem ao sebo somente quando o preço do óleo de soja estiver alto (Levy, 2011).

A dificuldade de coleta de grandes volumes de sebo para processamento contínuo (Andrade Filho, 2007).

A presença de irregularidades por parte dos produtores de sebo, dentre as quais, a falta de licenças ambientais (Levy, 2011).

\subsubsection{Baixa qualidade do sebo}

Um dos principais problemas relacionados à qualidade do sebo é a carência de normas técnicas que regulamentem a produção deste insumo e possibilitem a formação de um padrão de qualidade para o produto (Levy, 2011).

A obtenção de uma matéria-prima de baixa qualidade representa a geração de custos adicionais para a indústria de biodiesel, pois demanda a execução de pré-tratamentos do sebo e a purificação dos resíduos, bem como a produção de biocombustível de má qualidade (Leve, 2011). 
Consequentemente, este panorama denota perda de competitividade para o setor (Martins \& Carneiro, 2013).

\subsubsection{Características físico-químicas}

O sebo bovino apresenta elevado teor de ácidos graxos livres ( $A G L$ ), entre 0,5 e 4\%, o que diminui a eficiência do processo de produção de biodiesel e interfere na sua purificação, pois os AGL promovem a formação de sabões ao invés de biocombustível (Martins \& Carneiro, 2013; Barros \& Jardine, 2016b).

Em decorrência disso, é necessário realizar previamente um tratamento alcalino para precipitação dos AGL na forma de sabão, antes do início da transesterificação. Esse procedimento, por conseguinte, implica em modificações estruturais das plantas de biodiesel onerando os custos do processo, de maneira que pode equilibrar os valores em relação aos materiais de origem vegetal (Martins \& Carneiro, 2013).

A alta concentração de ácidos graxos saturados na composição do sebo influencia diretamente a qualidade de seu biodiesel, e esta é a principal preocupação para a utilização deste produto como combustível (Teixeira et al., 2010). Pois, os pontos de fusão de compostos de ácidos graxos saturados são significativamente mais elevados que os de compostos provenientes de ácidos graxos insaturados (Balen, 2012). Portanto, demonstram uma tendência maior à solidificação em baixas temperaturas (Cunha, 2008; Moraes, 2008).

Além do caráter saturado, outro fator importante é o tamanho da cadeia carbônica das moléculas que compõem o biodiesel. Pois estas características afetam as propriedades de fluxo a frio (PFF) e a viscosidade cinemática deste biocombustível (Lôbo, Ferreira \& Cruz, 2009; Isioma, Muhammad, Sylvester, Innocent \& Linus, 2013).

Em função de sua composição química, o biodiesel de sebo possui PFF desfavoráveis, apresentando, pois, altos pontos de névoa, de fluidez e de entupimento de filtro a frio (PEFF) (Lôbo et al., 2009; Balen, 2012). Em decorrência disso, este produto tende a solidificar a baixas temperaturas, podendo entupir filtros ou mesmo tornar-se espesso a ponto de não poder ser bombeado do tanque de combustível até o motor (Teixeira et al., 2010). Assim, as PFF são de grande importância, sobretudo quando da utilização do biodiesel em regiões de clima frio, configurando-se como um dos maiores desafios para seu uso como alternativa ao diesel mineral (Balen, Tanobe \& Yamamoto, 2015).

Na Tabela 7 são apresentadas as PFF para biodieseis produzidos a partir de óleo de soja e sebo. Observa-se que os pontos de névoa, de fluidez e PEFF dos biocombustíveis oriundos do sebo são bastante superiores aos produtos correspondentes obtidos da soja. Estes valores quando elevados são ruins para as PFF do biodiesel. A principal razão para tal é o caráter saturado das moléculas do biodiesel proveniente da matéria-prima animal. 
Tabela 7: Propriedades de fluxo a frio do biodiesel oriundo de óleo de soja e sebo.

\begin{tabular}{ccccc}
\hline Matéria-prima & Grupo alquila & Ponto de névoa $\left({ }^{\circ} \mathrm{C}\right)$ & Ponto de fluidez $\left({ }^{\circ} \mathrm{C}\right)$ & PEFF $\left({ }^{\circ} \mathrm{C}\right)$ \\
\hline Soja & Metil & 0,0 & $-2,0$ & $-2,0$ \\
Soja & Etil & 1,0 & $-4,0$ & - \\
Sebo & Metil & 17,0 & 15,0 & 9,0 \\
Sebo & Etil & 15,0 & 12,0 & 8,0 \\
\hline
\end{tabular}

Fonte: Adaptado de Balen (2012).

Adicionalmente, em função de seu perfil de ácidos graxos, o biodiesel de sebo apresenta alta densidade e viscosidade (Moraes, 2008). Estas propriedades afetam diretamente a atomização do combustível no sistema de injeção de motores a diesel. A alta viscosidade é caracterizada pela grande concentração dos ácidos esteárico e palmítico (Teixeira et al., 2010).

Segundo Balen et al. (2014), a viscosidade do biodiesel aumenta com o decréscimo da temperatura, isto também ocorre com o diesel. Um aumento significativo desta propriedade está associado a transições de um comportamento não-newtoniano, de modo a ocasionar mudanças nas propriedades relógicas de fluxo e consequentemente restringir a passagem do combustível.

As PFF e a viscosidade cinemática do biodiesel podem ser melhoradas misturando-se o biodiesel com diesel mineral ou com um biodiesel de menor teor de moléculas de caráter saturado. Outra possibilidade é uso de aditivos químicos (Hemmat, Ghobadian, Loghavi, Kamgar, Fayyazi, 2013; Isioma et al., 2013).

No Brasil, a fim de atenuar a alta densidade e viscosidade do biodiesel de sebo, e obedecer às especificações de qualidade exigidas pela legislação, a alternativa adotada por produtores de biodiesel é misturar óleo de soja, oriundo da agricultura familiar, ao sebo líquido. Esta medida possibilita a melhora de algumas propriedades do biodiesel, como as suas características de armazenamento e permite a sua introdução nos leilões realizados pela ANP sob o enquadramento do Selo Combustível Social (SCS) (Levy, 2011).

Os ésteres metílicos de ácidos graxos de origem animal são menos estáveis à oxidação que ésteres metílicos oriundos de óleos vegetais. Esta diferença se deve pela ausência de antioxidantes naturais nestes ésteres. Em que pese a sua constituição ser majoritariamente de ácidos graxos de cadeia saturada (Sendzikiene, Makareviciene \& Janulis, 2005).

Por fim, em função das características gerais do sebo, seu percentual de enxofre é bastante superior ao encontrado nos óleos vegetais (Barros \& Jardine, 2016b). Não obstante, apresenta-se aproximadamente sete vezes abaixo do limite máximo estabelecido pela Resolução ANP № 45, de 2014 (Tabela 8). Isso o torna, segundo Teixeira (2011), um combustível ecologicamente correto, uma vez que não emite gases ricos em dióxido de enxofre, maior responsável pelo aumento da chuva ácida. 
Tabela 8: Enxofre total $(\mathrm{mg} / \mathrm{kg})$ para biodieseis de diferentes matérias-primas.

\begin{tabular}{c|c}
\hline Matéria-prima & Enxofre total $(\mathrm{mg} / \mathrm{kg})$ \\
\hline Algodão & 0,3 \\
Dendê & 0,6 \\
Soja & 2,78 \\
Sebo & 1,4 \\
Limite ANP & máx. 10,0 \\
\hline
\end{tabular}

Fonte: Santos (2010); Giakoumis (2013); ANP (2014).

\section{SELO COMBUSTÍVEL SOCIAL}

A partir de setembro de 2015 a aquisição de matérias-primas de origem animal foi incluída pelo Ministério do Desenvolvimento Agrário (MDA) no Selo Combustível Social, através da Portaria № 337, na qual consta também a definição dos critérios para este processo de inclusão. Segundo Ministério de Desenvolvimento Agrário [MDA] (2015), para além desta inclusão, a referida portaria trouxe ainda maior clareza quanto "aos procedimentos técnicos e administrativos que devem ser adotados quando houver arranjos de aquisição de matéria-prima de origem animal, em especial para o sebo bovino".

Os procedimentos supramencionados serão adotados por produtores de biodiesel e pelo MDA, órgão gestor do SCS. Ademais, normativos posteriores detalharão os arranjos possíveis relativos à aquisição deste tipo de matéria-prima (MDA, 2015).

Anteriormente, o PNPB não contemplava estas matérias-primas com as mesmas isenções de impostos concedidas a outros insumos utilizados para a produção de biodiesel, notadamente os óleos vegetais (Martins \& Carneiro, 2013).

Assim, o sebo não se enquadrava no escopo do SCS, a despeito de a pecuária não ser uma atividade praticada exclusivamente por grandes produtores, mas também por pequenos e médios proprietários (Levy, 2011).

A inclusão do sebo bovino no SCS representa maiores incentivos para a cadeia produtiva desta matéria-prima e também pode possibilitar a sua expansão, reforçando a sua importância para a produção de biodiesel no país.

\section{CONSIDERAÇÕES FINAIS}

A relação entre vantagens e limitações afirma o sebo como uma matéria-prima com grande potencial produtivo para da cadeia produtiva do biodiesel no Brasil. Especialmente por se tratar de uma matéria-prima obtida como subproduto a baixo custo e com grande disponibilidade no país, da qual se obtém um biodiesel de qualidade com boas vantagens energéticas em comparação com o biodiesel de origem vegetal. Ademais, seu uso permite diversificar as fontes de matéria-prima, uma das propostas do PNPB; além de representar junto ao setor frigorífico uma alternativa rentável para este resíduo.

Alguns problemas, contudo, necessitam ser superados pela cadeia produtiva do sebo, como a carência de um mercado organizado e a falta de normas técnicas que regulamentem a sua 
produção e possibilitem a formação de um padrão de qualidade para este produto. De modo que possibilite a indústria de biodiesel adquirir matéria-prima de boa qualidade, evitando consequentemente a elevação nos custos de produção e ainda a obtenção de biocombustível fora dos padrões exigidos pela legislação.

\section{AGRADECIMENTOS}

Os autores agradecem à Fundação de Amparo à Pesquisa do Estado de Minas Gerais FAPEMIG, CAPES e CNPq.

\section{REFERÊNCIAS}

Associação Brasileira das Indústrias de Óleos Vegetais. (2016). Produção de biodiesel por matériaprima. Recuperado em 20 fevereiro, 2016, de http://www.abiove.org.br/site/busca.php?tag=biodiesel

Andrade Filho, M. (2007). Aspectos técnicos e econômicos da produção do biodiesel a partir do sebo bovino no Brasil.. Dissertação de Mestrado,Universidade Salvador, Salvador, BA, Brasil.

Resolução ANP № 45, de 25 de agosto de 2014. (2014). Dispõe sobre a especificação do biodiesel contida no Regulamento Técnico ANP no 3 de 2014 e as obrigações quanto ao controle da qualidade a serem atendidas pelos diversos agentes econômicos que comercializam o produto em todo o território nacional. Brasília, DF. Recuperado em 04 janeiro, 2016, de http://nxt.anp.gov.br/NXT/gateway.dll/leg/resolucoes_anp/2014/agosto/ra

np\%2045\%20-\%202014.xml?fn=document-frameset.htm\$f=templates\$3.0]

Aransiola, E. F., Ojumu, T. V., Oyekola, O. O., Madzimbamuto, T. F. \& Ikhu-Omoregbe, D. I. O. (2014). A review of current technology for biodiesel production: State of the art. Biomass and Bioenergy, 61, 276-297.

Balen, M. Aditivos melhoradores das propriedades de fluxo a frio em biodiesel. (2012). Dissertação de Mestrado, Universidade Federal do Paraná, Curitiba, PR, Brasil.

Balen, M., Tanobe, V. O. A., Yamamoto, C. I. (2014, outubro). Aditivos para a melhoria das propriedades de escoamento do biodiesel a frio. Anais do Congresso Brasileiro de Engenharia Química, São Paulo, SP, Brasil, XX.

Barros, T. D. \& Jardine, J. G. Biodiesel. (2016a). Recuperado em 17 fevereiro, 2016, de http://www.agencia.cnptia.embrapa.br/gestor/agroenergia/arvore/CONT000f837cz5s0z8kfsx 007poikmekcqea.html

Barros, T. D. \& Jardine, J. G. Gordura animal. (2016b). Recuperado em 24 fevereiro, 2016, de http://www.agencia.cnptia.embrapa.br/gestor/agroenergia/arvore/CONT000fj1om7kf02wyiv $802 \mathrm{hvm} 3$ jholyoom.html

Bello, E. I. \& Daniel, F. (2015). Optimization of groundnut oil biodiesel production and characterization. Applied Science Reports, 9, 172-180.

Cárdenas, O. (2011). Estudo comparativo da combustão de sebo bovino e diesel em fornalha calorimétrica flamotubular. Tese de Doutorado, Universidade de São Paulo, São Carlos, SP, Brasil.

Chen, J., Jia, L., Guo, X., Xiang, L. \& Lou, S. (2014). Production of novel biodiesel from transesterification over KF-modified Ca-Al hydrotalcite catalyst. Royal Society of Chemistry Advances, 4, 60025-60033. 
Cunha, M. E. (2008). Caracterização de biodiesel produzido com misturas binárias de sebo bovino, óleo de frango e óleo de soja. Dissertação de Mestrado, Universidade Federal do Rio Grande do Sul, Porto de Alegre, RS, Brasil.

Cunha Jr., A., Feddern, V., De Prá, M. C., Higarashi, M. M., De Abreu, P.G. \& Coldebella, A. (2013). Synthesis and characterization of ethylic biodiesel from animal fat wastes. Fuel, 105, 228-234.

De Quadros, D. P. C., Chaves, E. S., Silva, J.S.A., Teixeira, L. S. G., Curtius, A.J. \& Pereira, P.A.P. (2011). Contaminantes em Biodiesel e Controle de Qualidade. Revista Virtual Química, 3(5), 376-384.

Díaz, G. C. (2012). Hidrólise e hidrogenação simultânea (óleo de soja e de sebo bovino): efeito do metal suportado. Tese de Doutorado, Universidade Federal do Rio de Janeiro, Rio de Janeiro, RJ, Brasil.

Empresa de Pesquisa Energética. (2016). Análise de Conjuntura dos Biocombustíveis: Ano 2015. Recuperado em 15 fevereiro, 2016, de http://www.epe.gov.br/Petroleo/Documents/An\%C3\%A1lise\%20de\%20Conjuntura\%20dos\%2 OBiocombust\%C3\%ADveis\%20\%20boletins\%20peri\%C3\%B3dicos/An\%C3\%A1lise\%20de\%20Co njuntura\%20dos\%20Biocombust\%C3\%ADveis1\%20-\%20Ano\%202015.pdf.

Fernandes, D. M., Serqueira, D. S., Portela, F.M., Assunção, R. M. N., Muñoz, R. A. A., Terrones, M. G. H. (2012). Preparation and characterization of methylic and ethylic biodiesel from cottonseed oil and effect of tert-butylhydroquinone on its oxidative stability. Fuel, 97, 658661.

Giakoumis, E. G. (2013). A statistical investigation of biodiesel physical and chemical properties, and their correlation with the degree of unsaturation. Renewable Energy, 50, 858-878.

Glaude, P. A., Fournet, R., Bounaceur, R. \& Molière, M. (2010). Adiabatic flame temperature from biofuels and fossil fuels and derived effect on NOx emissions. Fuel Processing Technology, 91(2), 229-235.

Hemmat, Y., Ghobadian, B., Loghavi, M., Kamgar, S. \& Fayyazi, E. (2013). Biodiesel fuel production from residual animal fat as an inedible and inexpensive feedstock. International Research Journal of Applied and Basic Sciences, 5(1), 84-91.

Isioma, N., Muhammad, Y., SylvesteR, O., Innocent, D. \& Linus, O. (2013). Cold flow properties and kinematic viscosity of biodiesel. Universal Journal of Chemistry, 1(4), 135-141.

Krause. L. C. (2008). Desenvolvimento do processo de produção de biodiesel de origem animal. Tese de Doutorado, Universidade Federal do Rio Grande do Sul, Porto Alegre, RS, Brasil.

Levy, G. (2011). A inserção do sebo bovino na indústria brasileira de biodiesel: análise sob a ótica da economia dos custos de mensuração. Dissertação de Mestrado, Universidade de São Paulo, Piracicaba, SP, Brasil.

Lôbo, I. P., Ferreira, S. L. C. \& Cruz, R. S. (2009). Biodiesel: parâmetros de qualidade e métodos analíticos. Química Nova, 32(6), 1596-1608.

Martins, L. O. S. \& Carneiro, R. A. F. (2013). O sebo bovino como insumo estratégico da cadeia de biodiesel: uma análise crítica. Bioenergia em revista: diálogos, 3(1), 32-44.

Melo, M.A.M.F. (2010). Avaliação das propriedades de óleos vegetais visando a produção de biodiesel. Dissertação de Mestrado, Universidade Federal da Paraíba, João Pessoa, PB, Brasil.

Ministério da Agricultura, Pecuária e Abastecimento. (2014a). Benefícios ambientais da produção e do uso do biodiesel. Recuperado em 22 fevereiro, 2016, de http://www.bsbios.com/media/adminfiles/relatorio_biodiesel_p_web.pdf

Ministério da Agricultura, Pecuária e Abastecimento. (2014b). Plano mais pecuária. Recuperado em 23 fevereiro, 2016, de http://www.sgc.goias.gov.br/upload/arquivos/201402/mais_pecuaria.pdf 
Ministério da Agricultura, Pecuária e Abastecimento. (2016). Dados de rebanho bovino e bubalino no Brasil - 2015. Recuperado em 24 agosto, 2016, de http://www.agricultura.gov.br/arq_editor/file/Dados\%20de\%20rebanho\%20bovino\%20e\%20 bubalino\%20do\%20Brasil\%202015_site.pdf

Ministério do Desenvolvimento Agrário. (2015). Mudanças na portaria do Selo Combustível Social. $\begin{array}{lllll}\text { Recuperado em } 05 \text { janeiro, de } & \text { 2016, }\end{array}$ http://www.mda.gov.br/sitemda/noticias/mudan\%C3\%A7as-na-portaria-do-selocombust\%C3 \%ADvel-social

Moraes, M. S. A. (2008). Biodiesel de sebo: avaliação de propriedades e testes de consumo em motor a diesel. Dissertação de Mestrado, Universidade Federal do Rio Grande do Sul, Porto Alegre, RS, Brasil.

Neves, T. A. (2011). Tratamento físico-químico dos efluentes líquidos da produção de biodiesel metílico em regime de funcionamento contínuo e batelada. Dissertação de Mestrado, Universidade Federal de Mato Grosso, Cuiabá, MT, Brasil.

Pacheco, J. W. (2006a). Guia técnico ambiental de frigoríficos: industrialização de carnes bovina e suína (1aㅡ ed.). São Paulo: Cetesb.

Pacheco, J. W. (2006b). Guia técnico ambiental de graxarias (1a ed.). São Paulo: Cetesb.

Padula, A. D., Santos, M. S., Ferreira, L. \& Borenstein, D. (2012). The emergence of the biodiesel industry in Brazil: current figures and future prospects. Energy Policy, 44, 395-405.

Pires, A. (2012). Sebo bovino e o biodiesel. Recuperado em 22 abril, 2016, de http://www.biodieselbr.com/noticias/materia-prima/sebo/sebo-bovino-biodiesel-70812.htm

Rebouças, A. S., Zanini, A., Kiperstok, A., Pepe, I.M. \& Embiruçu, M. (2010). Contexto ambiental e aspectos tecnológicos das graxarias no Brasil para a inserção do pequeno produtor na indústria da carne. Revista Brasileira de Zootecnia, 39, 499-509.

Santos, A. G. D. (2010). Avaliação da estabilidade térmica e oxidativa do biodiesel de algodão, girassol, dendê e sebo bovino. Dissertação de Mestrado, Universidade Federal do Rio Grande do Norte, Natal, RN, Brasil.

Santos, V. C. (2014). Investigação e uso de sólidos baseados em compostos inorgânicos para a obtenção de ésteres metílicos a partir da catálise heterogênea de esterificação de ácidos graxos. Tese de Doutorado, Universidade Federal do Paraná, Curitiba, PR, Brasil.

Sendzikiene, E., Makareviciene, V. \& Janulis, P. (2005). Oxidation stability of biodiesel fuel produced from fatty wastes. Polish Journal of Environmental Studies, 14(3), 335-339.

Severgnini, K. \& Langer, M. (2011). Gordura animal: um novo destino; um novo combustível. Unoesc \& Ciência, 2(2), 157-164.

Silva, A. A. L., Santos, A. G. D., Di Souza, L., Caldeira, V. P. S., Luz Junior, G.E. \& Araújo, A.S. (2015). Síntese e caracterização de biodiesel de sebo bovino e de sua mistura B10. Orbital: Electronic Journal of Chemistry, 7(1), 21-27.

Tan T., Lu, J., Nie, K., Deng, L. \& Wang, F. (2010). Biodiesel production with immobilized lipase: a review. Biotechnology Advances, 28(5), 628-634.

Teixeira, L. S. G., Couto, M. B., Souza, G. S., Andrade Filho, M., Assis, J. C. R., Guimarães, P. R. B., Pontes, L. A. M., Almeida, S. Q. \& Teixeira, J.S.R. (2010). Characterization of beef tallow biodiesel and their mixtures with soybean biodiesel and mineral diesel fuel. Biomass and Bioenergy, 34, 438-441.

Teixeira, G. A. A. (2011). Avaliação do tempo de vida útil de biodiesel metílico obtido a partir da mistura de sebo bovino e óleos de soja e babaçu. Tese de Doutorado, Universidade Federal da Paraíba, João Pessoa, PB, Brasil. 
União Brasileira do Biodiesel e Bioquerosene. (2016). Biodiesel: combustível alinhado ao modelo de desenvolvimento global sustentável. Recuperado em 10 março, 2016, de http://www.ubrabio.com.br/sites/1800/1891/20151103BiodieselcombustAvelalinhadoaono.p df

Villela, H. D. M. (2014). Utilização das técnicas de engenharia genética e bioquímica em Chlamydomonas reinhardtii visando o aumento da produção de lipídeos para obtenção de biocombustível. Dissertação de Mestrado, Universidade de São Paulo, São Paulo, SP, Brasil.

Wang, H., Covarrubias, J., Prock, H., Wu, X., Wang, D. \& Bossmann, S.H. (2015). Acid-functionalized magnetic nanoparticle as heterogeneous catalysts for biodiesel synthesis. The Journal of Physical Chemistry C, 119(46), 26020-26028.

Yaakob, Z., Narayanan, B. N., Padikkaparambil, S., Unni, K. S. \& Akbar, P.M. (2014). A review on the oxidation stability of biodiesel. Renewable and Sustainable Energy Reviews, 35, 136-153. 